\title{
Skeletal abnormalities, hypocalcaemia and intracranial calcification
}

\author{
Rajashree Khot, Madhuri Paithankar, HR Salkar, VL Gupta, Ashish Satav
}

A 35-year-old man was admitted to the infectious ward with complaints of loose motions and vomiting four to five times a day and generalised stiffness with severe muscle cramps four hours prior to admission. On examination he had tachycardia, a blood pressure of $90 / 60 \mathrm{mmHg}$, cold extremities and a dry tongue suggestive of moderate dehydration. He was conscious, well oriented, had generalised rigidity and carpopedal spasm. His serum calcium was $1.8 \mathrm{mmol} / 1$ (normal $2.2-2.6 \mathrm{mmol} / \mathrm{l}$ ). He was given intravenous fluids, calcium gluconate, vitamin $\mathrm{D}_{3}$, ampicillin, and metronidazole, and he improved.

His history revealed that he was mentally retarded from birth. He had been operated for cataract in both eyes four years earlier, and he had had a few episodes of carpopedal spasm. His physical appearance is shown in figure 1. A radiological skeletal survey revealed short metacarpals, a calcified sesamoid bone and bilateral capsular calcification of the hip joint. Computed tomography (CT) scan of the head was performed (figure 2). Laboratory investigations were normal except serum phosphate and serum parathyroid hormone levels, which were elevated.

Department of
Medicine, Government
Medical College,
Nagpur 440001, India
R Khot
M Paithankar
H R Salkar
V L Gupta
A Satav
Correspondence to
Dr R S Khot,
52 New Ramdaspeth,
Nagpur-440010, India

Accepted 9 July 1997
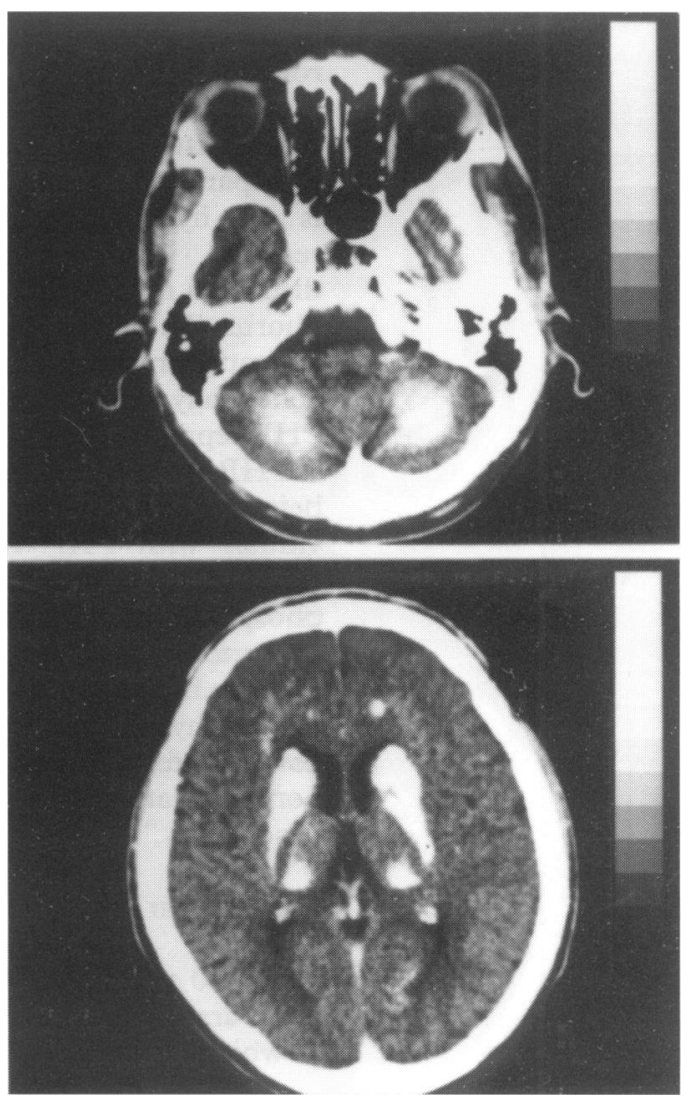

Figure 1 Photograph of the patient showing physical and skeletal abnormalities

Figure 2 CT scan of the patient's head

2 What are the CT findings observed in figure 2 and how do they correlate with the physical, radiological and biochemical findings?

3 What is the diagnosis and what are its variants?

\section{Questions}

1 What are the various physical abnormalities observed in figure 1 ? 


\section{Answers}

QUESTION 1

As seen in figure 1, the patient was shortstatured and mildly obese, with a large round head. $\mathrm{He}$ has short extremities, and small hands with short, blunt digits. $\mathrm{He}$ also has short, stubby toes. All these physical findings point towards complete expression of $\mathrm{Al}$ bright's hereditary osteodystrophy.

\section{QUESTION 2}

CT scan of the head shows massive calcification involving the thalamus, caudate nucleus, lentiform nucleus, anterior limb of internal capsule on both sides and both cerebellar hemispheres. There is no evidence of hydrocephalus or cerebral oedema. These findings, along with the associated skeletal abnormalities, biochemical abnormalities suggestive of hypocalcaemia, hyperphosphataemia, elevated levels of serum parathyroid hormone, mental retardation, and cataract, constitute the completely expressed sydrome of pseudohypoparathyroidism (PHP) or Albright's hereditary osteodystrophy.

\section{QUESTION 3}

This is a classical case of pseudohypoparathyroidism (PHP), probably type Ia, with $\mathrm{Al}$ bright's hereditary osteodystrophy. Similar manifestations are also seen in pseudopseudohypoparathyroidism (PPHP) except that there is no hypocalcaemia, and an absence or reduced incidence of certain sequelae of disturbed metabolism of calcium and/or phosphorus. There is positive evidence that PPHP is simply an incompletely expressed form of a genetically determined abnormality of which PHP represents the complete syndrome. ${ }^{2}$

PHP is classified into types I and II, type I being subclassified into Ia and Ib (table). Individuals with PHP type I show a deficient response in urinary cyclic adenosine monophosphate (cAMP) following administration of exogenous parathyroid hormone. PHP type II patients have a normal urinary cAMP response to parathyroid hormone and are assumed to have a defect in their response to parathyroid hormone at a locus beyond that of cAMP production. $^{3}$

\section{Discussion}

Some 20 years ago, Albright, Burnett, Smith and Parson first drew attention to a syndrome in which certain skeletal abnormalities coexist

Table Working classification of PHP

\begin{tabular}{|c|c|c|c|c|}
\hline Type & PHP-Ia & PHP-Ib & PHP-II & PPHP \\
\hline Hypocalcaemia & + & + & + & - \\
\hline Hyperphosphataemia & + & + & + & \pm \\
\hline Albright's hereditary osteodystrophy & + & - & - & + \\
\hline Serum parathyroid hormone & $\uparrow$ & $\uparrow$ & $\uparrow$ & $\mathbf{N}$ \\
\hline GS subunit defect & + & - & - & + \\
\hline Response of urinary cAMP to parathyroid hormone & $\uparrow$ & $\uparrow$ & $\mathbf{N}$ & $\mathbf{N}$ \\
\hline \multirow{2}{*}{$\begin{array}{l}\text { Resistance to hormones in addition to parathyroid } \\
\text { hormone }\end{array}$} & & & & \\
\hline & + & - & - & + \\
\hline
\end{tabular}

with chemical and clinical findings characteristic of hypoparathyroidism. ${ }^{1}$ The chemical derangements (hypocalcaemia, hyperphosphataemia) found in all three cases originally reported were refractory to correction by administration of parathyroid extract. The authors inferred that the renal tubule was failing to respond to an adequate quantity of circulating parathyroid hormone and christened the condition pseudohypoparathyroidism. ${ }^{2}$ In PHP, females outnumber males 2:1 and the disorder has a genetic basis in at least one third of the reported patients. Most patients with Albright's hereditary osteodystrophy in full have decreased activity of the guanine nucleotide-binding protein (GS protein) that stimulates adenylyl cyclase. The gene encoding the alpha-subunit of the GS protein (GNAS1) has been mapped to the long arm of chromosome 20 . In some patients there may be a single base substitution of GS gene due to an inherited mutation in a human $G$ protein. ${ }^{4}$ Cases have been reported of unrelated individuals with apparent Albright's hereditary osteodystrophy, associated with small terminal deletions of chromosome $2 . \operatorname{Del}(2)$ (q37) is the first consistent karyotypic abnormality that has been documented in Albright's hereditary osteodystrophy. The deletion of the same small terminal in unrelated individuals with a similar phenotype suggests that a gene locus in $2 \mathrm{q} 37$ region is important in the pathogenesis of Albright's syndrome. The association of Albright's hereditary osteodystrophy and the GNASI locus on chromosome 20 is well documented. The observation of a second potential disease locus on chromosome 2 may help explain the heterogeneity observed in this disorder. ${ }^{5}$ Albright's hereditary osteodystrophy is associated with PHP and PPHP. Various clinical features are summarised in boxes 1 and 2 .

The essential biochemical abnormalities in PHP are hypocalcaemia and hyperphosphataemia. Excessive secretion of parathyroid hormone is the consequence of hyperplasia of the parathyroids, a response to resistance to the action of parathyroid hormone. This can occur in three forms: combined renal and skeletal resistance, skeletal resistance with a normal renal response (these patients exhibit a phosphaturic response to exogenous administration

\section{Albright's hereditary osteodystrophy:} clinical features

- short stature (less than 60 inches)

- round face

- dental aplasia or delayed dentition

- metacarpal and metatarsal abnormalities

- exostoses

- subcutaneous calcification, ossification

- lenticular calcification

- thickened calvarium

- mental retardation

- basal ganglia calcification

- history of tetany or convulsions

- family history of some related abnormalities 


\begin{tabular}{|l|}
\hline Features occasionally present in PHP \\
and PPHP \\
\hline - endocrinopathies: diabetes mellitus, \\
hypothyroidism \\
- delayed puberty: hypomenorrhoea, diabetes \\
insipidus, low 17-ketosteroid excretion \\
- genu valgum \\
radius curvus \\
- blue sclerae \\
gonadal dysgensis \\
\hline
\end{tabular}

Box 2

of parathyroid hormone), and renal resistance with conserved skeletal receptivity. Thus a

1 Yendt ER. In: Spittel JA, ed. Clinical Medicine. Endocrinology, vol 8. Philadelphia: Harper \& Row, 1983;pp 11-23.

2 Mann JB, Alterman S, Hills AG. Albright's hereditary osteodystrophy comprising 'pseudohypoparathyroidism' and 'pseudopseudohypoparathyroidism'. Ann Intern Med 1962;56:315-39.

3 Drezner M, Neelon FA, Lebovitz HE, et al. 'Pseudopseudohypoparathyroidism' type II. A possible defect in the reception of the cyclic AMP signal. N Engl f Med 1973;289:1056. spectrum of disease can be envisioned. ${ }^{6} \mathrm{~A}$ working classification of the different forms of $\mathrm{PHP}$ is given in the table.

PHP and PPHP are treated by vitamin D and calcium supplementation. Early treatment may correct altered calcium and phosphorus levels and diminish the skeletal effects of osteitis fibrosa.

\section{Final diagnosis}

Pseudohypoparathyroidism with Albright's hereditary osteodystrophy.

Keywords: Albright's hereditary osteodystrophy; hypocalcaemia; parathyroid hormone; pseudohypoparathyroidism.

4 Patten JL, Donald RJ,Valle D, et al. Mutation in the gene encoding the stimulatory $G$ protein of adenylate cyclase in AHO. N Engl $\Im$ Med 1990;322:1412-9.

5 Phelan MC, Rogers RC, Clarkson KB, et al. Albright's hereditary osteodystrophy and del (2) (q37.3) in four unrelated individuals. Am $\mathcal{F}$ Med Genet 1995;58:1-7.

6 Frame B, Hanson C, Frost HM, et al. Renal resistance to parathyroid hormone with osteitis fibrosa 'pseudopseudohypoparathyroidism'. Am $\mathcal{F}$ Med 1972;52:31 1-21.

\title{
An overweight woman with galactorrhoea
}

\author{
WS Chow, KSL Lam
}

A 32-year-old Filipino maid was referred to our Endocrine Clinic in Queen Mary Hospital because of galactorrhoea and hyperprolactinaemia. She had regular menstruation, but had developed persistent galactorrhoea after her last delivery 10 years ago. Medical consultation was sought because of increased galactorrhoea in recent months.

From September 1995 to April 1996, her body weight decreased from $55 \mathrm{~kg}$ to $49.5 \mathrm{~kg}$ while she put herself on Triac (3,5,3'-triiodothyroacetic acid) $1.05 \mathrm{mg}$ daily. She stopped the drug one month before her first visit to the Endocrine Clinic. Physical examination confirmed the presence of galactorrhoea, but visual field and fundoscopy were normal. Her pulse was 90 beats $/ \mathrm{min}$ and hands were warm. There was no palpable goitre or delayed relaxation of tendon reflexes.

In May 1996, investigations revealed hyperprolactinaemia with prolactin levels of 1610 and $1440 \mathrm{mIU} / 1$ (normal range, $<500 \mathrm{mIU} / \mathrm{l}$ ) on two occasions. Thyroid function tests showed low free thyroxine ( $3 \mathrm{pmol} / 1$; normal $10-19 \mathrm{pmol} / \mathrm{l})$ and thyroid-stimulating hormone (TSH) $(<0.03$ $\mathrm{mIU} / 1$; normal 0.35-5.5 mIU/l) levels. Other anterior pituitary hormones were normal.

A thyrotropin-releasing hormone (TRH) test was done in August 1996, four months after drug

Division of

Endocrinology,

University

Department of

Medicine, Queen Mary

Hospital, Pokfulam

Road, Hong Kong

WS Chow

KSL Lam

Correspondence to Prof Karen SL Lam

Accepted 23 July 1997 cessation (table). By this time, free thyroxine and TSH had increased to $9 \mathrm{pmol} / 1$ and $1.9 \mathrm{mIU} / 1$, respectively, and her prolactin level had decreased to $840 \mathrm{mIU} / 1$, although galactorrhoea was still present. Magnetic resonance imaging of the pituitary revealed no abnormality.

Table TRH test (August 96)

\begin{tabular}{llll}
\hline & $0 \min$ & $20 \min$ & $60 \min$ \\
\hline TSH (mIU/l) & 1.9 & 16 & 12 \\
Free T4 (pmol/) & 9.0 & 9.0 & 9.0 \\
\hline
\end{tabular}

\section{Questions}

1 What are the common causes of hyperprolactinaemia?

2 How do you differentiate between primary and secondary hypothyroidism?

3 What was the underlying diagnosis? 